\title{
Fluoride Binding and Crystal Field Analysis of Lanthanide Complexes of Tetrapicolyl-Appended Cyclen
}

\author{
Octavia A. Blackburn, ${ }^{[a]}$ Alan M. Kenwright, ${ }^{[b]}$ Andrew R. Jupp, ${ }^{[a]}$ Jose M. Goicoechea, ${ }^{[a]}$ Paul D. \\ Beer, ${ }^{[a]}$ and Stephen Faulkner*[a] \\ Dedication ((optional))
}

\begin{abstract}
Lanthanide complexes of tetrapicolyl cyclen display remarkably high affinities for fluoride $(\log K \sim 5)$ in water, and are shown to form 1:1 complexes. The behaviour of these systems can be rationalised by changes to the magnitude of the crystal field parameter, $\mathrm{B}_{0}{ }^{2}$. However, such changes are not invariably accompanied by a change in sign of this parameter: for early lanthanides the N8 donor set with a coordinated axial water molecule ensures that the magnetic anisotropy has the opposite sense to that observed in the analogous dehydrated lanthanide complexes.
\end{abstract}

\section{Introduction}

Paramagnetic lanthanide ions play a key role in a wide variety of applications, ranging from magnetic materials and optical devices through to medical imaging and assay. ${ }^{[1]}$ For many years, the theories propounded by Bleaney have been used to explain the magnetic, optical and spectroscopic behaviour of such systems on the basis of the magnetic anisotropy at the lanthanide centre, ${ }^{[2]}$ and these treatments are covered in a number of excellent reviews on the treatment of NMR data of paramagnetic lanthanide complexes. [ 3 ] However, it is increasingly clear that, while these theories provide an effective qualitative rationalization of the behaviour of lanthanide complexes, they do not provide an invariably reliable basis for a predictive understanding of the behaviour of lanthanide complexes. ${ }^{[4]}$

Bleaney made a number of explicit approximations; specifically that lanthanide ions can be treated in terms of a point dipole centred on the nucleus, that the ligand field parameters $\mathrm{B}_{0}{ }^{2}$ and $\mathrm{B}_{2}{ }^{2}$ are small compared to $\mathrm{kT}$, and that higher order ligand field terms need not be considered. These assumptions simplify the theory to the point that it becomes relatively easy to handle, but they are not universally valid. Indeed, over the course of the last forty years, a number of cases have been observed where it is clear that this approach is insufficient to explain a range of spectroscopic and magnetic

[a] Dr. O. A. Blackburn, Dr. Andrew R. Jupp, Prof. Jose Goicoechea Prof. S. Faulkner

Chemistry Research Laboratory, Oxford University,

12 Mansfield Road, Oxford OX1 3TA (UK)

E-mail: stephen.faulkner@keble.ox.ac.uk.

[b] Dr. Alan M. Kenwright

Department of Chemistry, University of Durham

South Road, Durham DH1 3LE (UK)

Supporting information for this article is given via a link at the end of the document observations. [ 5 l Recently, developments in theoretical approaches have shown considerable promise. ${ }^{[6]}$ Testing these approaches requires a body of data on well-defined systems, and we and others have been exploring the use of kinetically stable lanthanide complexes to provide information about anisotropy at the metal centre through the use of optical, NMR and EPR methods. ${ }^{[4]}$

Analysis and understanding of the crystal field effects on the properties of lanthanide complexes has become of great interest, especially in the field of molecular magnetism. ${ }^{[7]} \mathrm{We}$ have studied the effects of fluoride binding on the nature of the crystal field in lanthanide complexes of DOTA-tetraamide ligands such as LnDTMA (Scheme 1). [8,9] We witnessed dramatic changes to the spectroscopic properties owing to a switch in magnetic anisotropy from prolate to oblate (or vice versa) upon replacement of an axially coordinated water molecule by fluoride. Changing the nature of the peripheral substituents on these ligands has subtle effects on the fluoride binding event as a result of differing solvent order and ligand electron donating ability. ${ }^{[10]}$ The residual charge on the lanthanide centre, which is determined by the electron donating properties of the ligand, has a significant effect on the association constant with fluoride, although $K$ is also influenced by other factors.

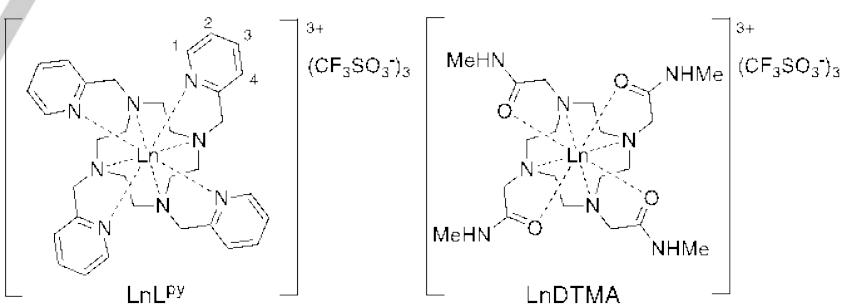

Scheme 1. Structure of the $L L^{p y}$ complexes studied in this paper (showing atom labels used in assignments) together with the structure of LnDTMA shown for comparison.

A previous study of lanthanide complexes of 1,4,7,10tetrakis(2-pyridylmethyl)-1,4,7,10-tetraaza-cyclododecane ( ${ }^{\text {py }}$ Scheme 1) revealed particularly narrow NMR spectral widths for ligand protons in comparison with DOTA-type systems. ${ }^{[11]}$ This would imply a small crystal field splitting owing to the relatively weak pyridyl donors. This system was analysed in depth by Kuprov, who used an approach derived from Maxwell's equations combined with a non-point electron probability density to rationalize observed behaviour in the system. ${ }^{[6 a]}$ Given the relatively weak electronic demands of the N8 donor set, we reasoned that fluoride binding would be likely to give rise to an increase in anisotropy at the lanthanide. We now report a study 
of these fluoride bound systems, and explore the nature of the crystal field in this system in more depth.

\section{Results and Discussion}

\section{Fluoride Binding}

Fluoride binding by $\mathrm{LnL}^{\mathrm{py}}$ complexes was studied by NMR and luminescence methods. As with our earlier studies on positively charged complexes, the proton NMR spectra display resonances corresponding to a fluoride adduct which are in slow exchange with those of the original species. The EuL ${ }^{p y}$ and $\mathrm{YbL}^{\mathrm{py}}$ emission spectra show marked changes in intensity and structure on addition of fluoride corresponding to a change in the crystal field around the lanthanide (see below).

The binding constants for association of fluoride with EuL ${ }^{p y}$ and $\mathrm{YbL}^{\mathrm{py}}$ were determined by both ${ }^{1} \mathrm{H}$ NMR and luminescence titration in $\mathrm{D}_{2} \mathrm{O}$ (Table 1). The data was fitted to a 1:1 binding model using the Dynafit program. ${ }^{[12]}$ During titration of fluoride the ${ }^{1} \mathrm{H}$ NMR integrals of both original and new peaks (see SI for spectra) were recorded relative to the internal standard DSS (4,4-dimethyl-4-silapentane-1-sulfonic acid). The same event was monitored using changes in the emission intensity from the lanthanide centres. Overlap of confidence intervals indicates that the same event is being monitored by both techniques, although the upper limits could not be defined in the case of $\mathrm{YbL}^{\mathrm{py}}$. From these results, there is no apparent difference in log $K_{a}$ between the EuL ${ }^{p y}$ and $\mathrm{YbL}^{\mathrm{py}}$. This contrasts with the tetraamide system, LnDTMA, where the association constant was found to decrease with decreasing ionic radius of the lanthanide ion. ${ }^{[9]}$

Table 1. $\log K_{a}$ values for 1:1 association with sodium fluoride measured by ${ }^{1} \mathrm{H}$ NMR and luminescence in $\mathrm{D}_{2} \mathrm{O}$ at $298 \mathrm{~K}$ with $95 \%$ confidence intervals given in parentheses.

\begin{tabular}{lll}
\hline & EuL $^{\text {py }}$ & YbL $^{\text {py }}$ \\
\hline Luminescence & $5.5[5.4-6.4]$ & $5.3[>4.6]^{[a]}$ \\
${ }^{1}$ H NMR & $5.0[4.8-5.5]$ & $5.2[>4.2]^{[a]}$ \\
\hline
\end{tabular}

[a] Upper limit could not be defined.

The affinity of these complexes for fluoride is dramatically higher than in the tetraamide systems studied by us and other groups ${ }^{[9,13]}$ However, large binding constants for fluoride have recently been reported for $\mathrm{C}_{2}$ symmetric singly charged europium complexes incorporating two aromatic donor groups and two carboxylic acid donors. ${ }^{[14,15]}$ Where the aromatic group is indazole, hydrogen bonding interactions stabilise a binuclear system in which two complexed lanthanide centres are linked by bridging fluoride: in this system, a log $K_{a}$ value of 13.0 was obtained for a 2:1 binding event. ${ }^{[14]}$ In a related quinoline-based system, a 1:1 binding of fluoride with $\log K_{a}=4.1($ at $\mathrm{pH}=6)$ was measured. ${ }^{[15]}$ The affinity of our $\mathrm{C}_{4}$-symmetric tetrapicolyl complexes for fluoride is comparable to these $\mathrm{C}_{2}$-symmetric systems. The slightly higher affinity of EuL py for fluoride in comparison with the quinoline-based system may be attributed to the higher residual charge on the lanthanide. Others have studied a $\mathrm{C}_{2}$ symmetric dipicolyl/diacetamide analogue, which showed a much lower association constant of log $K_{a}=2.9,{ }^{[13]}$ demonstrating that four picolyl donors are necessary to access this higher affinity and that the identity of the aromatic donor group is important.

\section{X-ray Crystallography}

A single crystal $X$-ray diffraction study revealed the structure of $\left[\mathrm{EuL}^{\mathrm{py}}(\mathrm{F})\right]\left[\mathrm{CF}_{3} \mathrm{SO}_{3}\right]_{2} \cdot \mathrm{H}_{2} \mathrm{O}$ (see $\mathrm{SI}$ for details). The cation sits atop a two-fold symmetry axis, which is coincident with the Eu-F bond, and thus only half of the molecule is observable in the asymmetric unit. The Eu-F interaction is relatively short at 2.171(4) $\AA$, and is similar to the only other crystallographically authenticated $\mathrm{Eu}$ complex bearing a terminal fluoride anion (2.193(7) $\AA$ and 2.197(8) $\AA$; two distinct molecules in the asymmetric unit). ${ }^{116]}$ There is no apparent intramolecular stabilisation of the fluoride by aromatic $\mathrm{C}-\mathrm{H} \cdots \mathrm{F}^{-}$interactions, as reported recently by Butler in a computed structure of a related europium fluoride complex. ${ }^{[15]}$
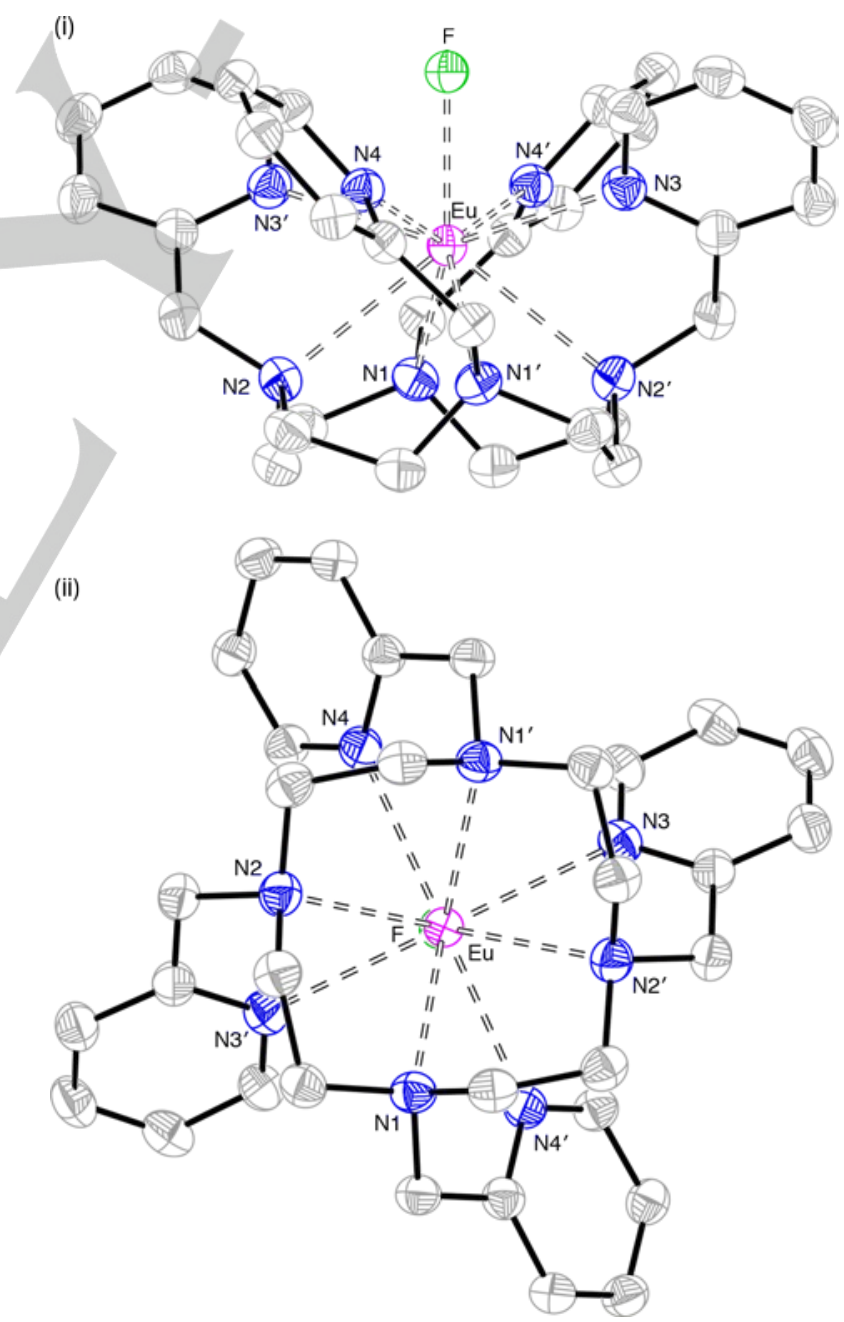

Figure 1: (i): Molecular structure of the $\operatorname{EuL}^{\mathrm{py}}(\mathrm{F})$ cation, and (ii): the same structure looking up the Eu-F bond. Anisotropic displacement ellipsoids are 
set at $30 \%$ probability. Hydrogen atoms, water of crystallisation and triflate anions are omitted for clarity. Selected bond lengths $(\AA)$ : Eu-F: 2.171(4), EuN1: 2.713(5), Eu-N2: 2.696(5), Eu-N3: 2.571(5), Eu-N4: 2.582(5). Symmetry element ': $-x,-y,+z$

The tetrapicolyl cyclen ligand coordinates to the Eu centre through the eight $\mathrm{N}$ atoms in an analogous manner to the previous structurally characterised lanthanide complexes of L $^{\text {py }}{ }^{[11]}$ Comparison of distances and torsion angles with these previous structures (Table S2) reveals that by far the most striking difference is the Ln-axial donor distance which is considerably shorter with fluoride in the ninth coordination site. There is also a slight displacement of the lanthanide ion towards the axial donor in $\mathrm{EuL}^{\mathrm{py}}(\mathrm{F})$ in comparison with the other structures, particularly those with neutral axial donors, suggesting this may be a consequence of electrostatics. A comparison of $\mathrm{EuL}^{\mathrm{py}}(\mathrm{F})$ with the closest crystallographically characterised hydrated complex, $\mathrm{GdL}^{\mathrm{py}}\left(\mathrm{OH}_{2}\right)$, is useful in establishing any differences in ligand structure which may be relevant to the solution-state studies below. Unfortunately the twinning in the published crystal means a detailed comparison of bond metric data is not possible. Nevertheless, there is a remarkable coordinative similarity of the octadentate ligand framework in both the Eu (fluoride-bound) and Gd (water-bound) structures that implies that any changes in crystal field effects at the lanthanide centre can be attributed to the identity of the axial ligand and not to a change in ligand structure.

There are two distinct elements of chirality in these molecules arising from the torsion angles within the cyclen ring ( $\delta \delta \delta \delta$ or $\lambda \lambda \lambda \lambda$ ), and the handedness of the twist of the pendant picolyl ligands $(\Delta$ or $\Lambda)$ as they ensure a close contact with the lanthanide centre (Scheme S1) ${ }^{[11]}$ The stereoisomeric forms can interconvert in solution via cyclen ring inversion and pendant arm rotation (see below). EuL ${ }^{\text {py }}(\mathrm{F})$ crystallised in the chiral space group $P 2{ }_{1} 2{ }_{1} 2$, and analysis of the Flack parameter $(-0.0150(12))$ revealed a pure composition with the absolute configuration shown $(\Lambda(\delta \delta \delta \delta))$. Solution-state spectroscopic studies imply the presence of diastereoisomers corresponding to a twisted square antiprismatic (TSAP) geometry at the metal, although only the SAP form crystallised in this case.

\section{Crystal Field Analysis}

Having established that these results show high affinity between $\mathrm{LnL}^{\text {py }}$ complexes and fluoride, we resolved to explore the nature of the effects on the lanthanide crystal field in detail. Such an analysis is facilitated by the clear similarities in structure between the fluoride-bound and water-bound species described above, which allow us to assign observed effects unequivocally to changes in anisotropy at the metal centre.

The nature of the crystal field in $\mathrm{LnL}^{\text {py }}$ complexes across the lanthanide series was examined in detail by analysis of the lanthanide-induced shifts (LIS) of the ${ }^{1} \mathrm{H}$ NMR signals of the ligand. For lanthanides with minimal contact contribution to the LIS, the shifts can be directly analysed using the equation proposed by Bleaney: ${ }^{[2]}$
$\ddot{o}_{P C}=\frac{2 C_{3} \beta^{2}}{(k T)^{2}} \frac{\left(3 \cos ^{2} \theta-1\right)}{r^{3}} B_{i 1}^{2}=D_{1} \frac{\left(3 \cos ^{2} \theta-1\right)}{r^{3}}$

Since values of the geometric parameter $\left(3 \cos ^{2} \theta \square 1\right) / r^{3}$ can be estimated from $X$-ray crystal structures by measuring the position of the hydrogen atoms using appropriate bond lengths and angles, a plot of $\left(3 \cos ^{2} \theta-1\right) / r^{3}$ vs. LIS should give a straight line whose gradient $\left(D_{1}\right)$ depends on the Bleaney coefficient $C_{J}$ and the second order crystal field parameter $\mathrm{B}_{0}{ }^{2}$. The sign and magnitude of the crystal field parameter gives us information about the crystal field through its effect on the magnetic anisotropy of the lanthanide ion. For lanthanides with a substantial contact shift contribution, Equation [1] cannot be used to directly access $\mathrm{B}_{0}{ }^{2}$ and Reilley analysis (vide infra) must instead be used to separate the contributions and characterise the crystal field. ${ }^{[17]}$

In order to implement these analyses, the proton resonances must first be assigned. The small crystal field splitting, and hence small pseudocontact shift contribution, of these complexes makes assignment difficult since the contact shift contributes heavily to the overall LIS. For the first half of the series, from $\mathrm{Ce}^{3+}$ to $\mathrm{Eu}^{3+}$, the lines are relatively narrow and assignment can be achieved using a combination of 2D COSY and NOESY experiments (assignments are presented in Table S3). The complexes are dominated by one isomer up to $\mathrm{Eu}^{3+}$ where ca. $15 \%$ of the species in solution are a minor isomer.

The 2D EXSY spectra of these complexes are dominated by one set of cross peaks, in contrast to [LnDOTA] ${ }^{-}$and related complexes that display three cross peaks per proton resonance. ${ }^{[18]}$ This implies that one mechanism of isomerism, either arm rotation or ring inversion, is much more favourable than the other. Since both the major and minor isomers of EuL ${ }^{\text {py }}$ are assigned directly, the EXSY spectrum can be used to identify the low energy isomerisation pathway (Scheme S1). The EXSY spectrum shows exchange of axial and equatorial protons between major and minor species, which implies that ring inversion is the favoured mechanism. Isomerisation via arm rotation might be expected to be disfavoured in aqueous solvents owing to the hydrophobic nature of the pyridyl arms which would result in significant solvent reorganisation upon rearrangement. This conclusion aids the assignment of other $\mathrm{LnL}^{\text {py }}$ complexes by inferences based on EXSY spectra.

Assignment of the proton spectra of $L L^{\text {py }}$ for the latter half of the lanthanide series is more challenging due to large linewidths, which severely limit the use of 2D NMR spectra. Furthermore, the proportions of minor isomers are greater than for the first half of the series resulting in extensive peak overlap; hence direct assignment of the proton spectra of most of the later lanthanide complexes is not possible. ${ }^{[11]}$ Fortunately, for $\mathrm{YbL}^{\mathrm{py}}$, there is only ca. $20 \%$ minor isomer present in $\mathrm{D}_{2} \mathrm{O}$ at 298 $\mathrm{K}$ and the lines are sufficiently sharp that the proton spectra of the major and minor isomers could be assigned with the aid of COSY, major/minor exchange patterns in the EXSY spectrum (which allow axial and equatorial protons to be identified) and the Bleaney relationship. 

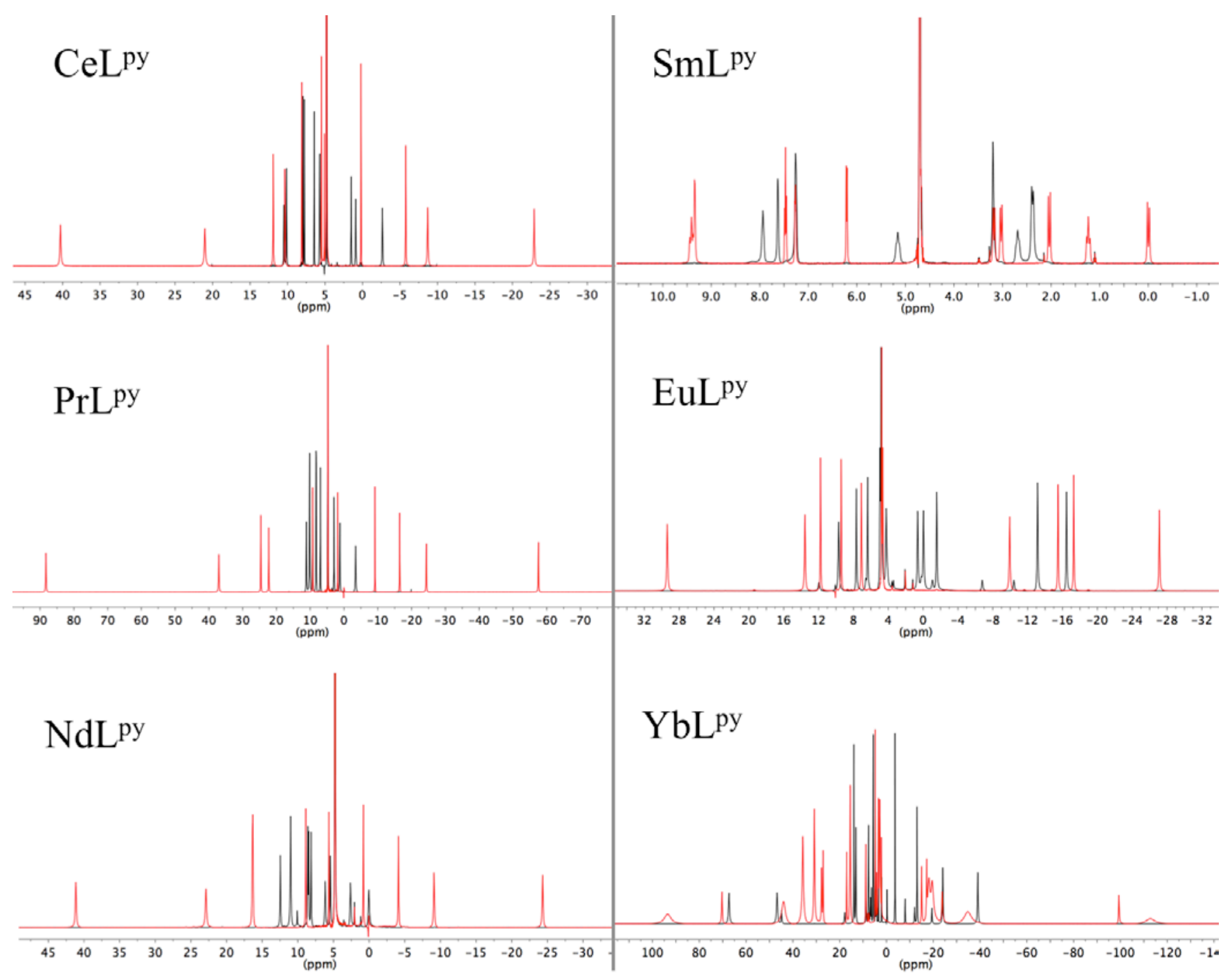

Figure 2. ${ }^{1} \mathrm{H}$ NMR spectra of $\mathrm{Ce}, \mathrm{Pr}, \mathrm{Nd}, \mathrm{Sm}, \mathrm{Eu}$ and $\mathrm{Yb}$ complexes of $\mathrm{L}^{\mathrm{py}}$ in the absence of fluoride (black), and excess $\mathrm{NaF}$ (red), in $\mathrm{D}_{2} \mathrm{O}$ at $298 \mathrm{~K}$.

The ${ }^{1} \mathrm{H}$ NMR spectra of complexes Ce-EuL ${ }^{\text {py }}$ and $\mathrm{YbL}^{\mathrm{py}}$ are shown in Figure 2 before and after addition of an excess of sodium fluoride. For all of the complexes, the new set of peaks has a larger shift range than the original set. For EuL ${ }^{p y}$, the proportion of minor isomer decreases to around $3 \%$ on addition of fluoride, and for all of the other early lanthanide complexes the amount of minor isomer is negligible. The spectrum of $\mathrm{YbL}^{\mathrm{py}}$ with fluoride is more complicated with ca. $30 \%$ being a minor isomer and the major isomer displaying particularly broad lines. Figure 3 demonstrates that the europium species are in slow exchange on this timescale: both sets of signals are observed when less than one equivalent of fluoride is added. Once excess fluoride has been added, the original set of peaks is no longer visible, in contrast with complexes of the tetraamides, where the hydrated species was always present. ${ }^{\left[{ }^{[}\right]}$

The ${ }^{1} \mathrm{H}$ NMR spectra of fluoride bound isomers of $\mathrm{YbL}^{\mathrm{py}}$ are assigned based on EXSY and COSY of a sample containing excess fluoride and EXSY of a sample containing a mixture of species on this timescale. $T_{1}$ measurements also aid the

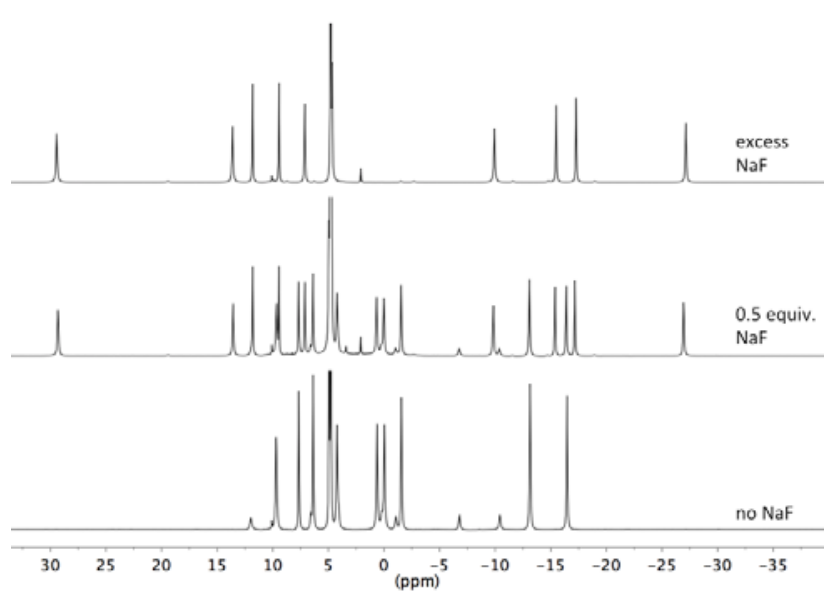

Figure 3. ${ }^{1} \mathrm{H}$ NMR spectra of EuL ${ }^{\text {py }}$ in the absence of fluoride (bottom), with ca. 0.5 equivalents of $\mathrm{NaF}$ (middle), and excess $\mathrm{NaF}$ (top), in $\mathrm{D}_{2} \mathrm{O}$ at $298 \mathrm{~K}$. 
assignment. Bleaney plots based on the $\mathrm{YbL}^{\mathrm{py}}\left(\mathrm{OH}_{2}\right)$ crystal structure $^{[11]}$ are shown for both isomers in the presence and absence of fluoride in Figure 4. To take account of the diamagnetic contributions to the shifts, the ${ }^{1} \mathrm{H}$ chemical shifts of the major isomers of the $\mathrm{LaL}^{\text {py }}$ complex in the presence and absence of fluoride, ${ }^{[11]}$ were used in the calculation of the LIS. In
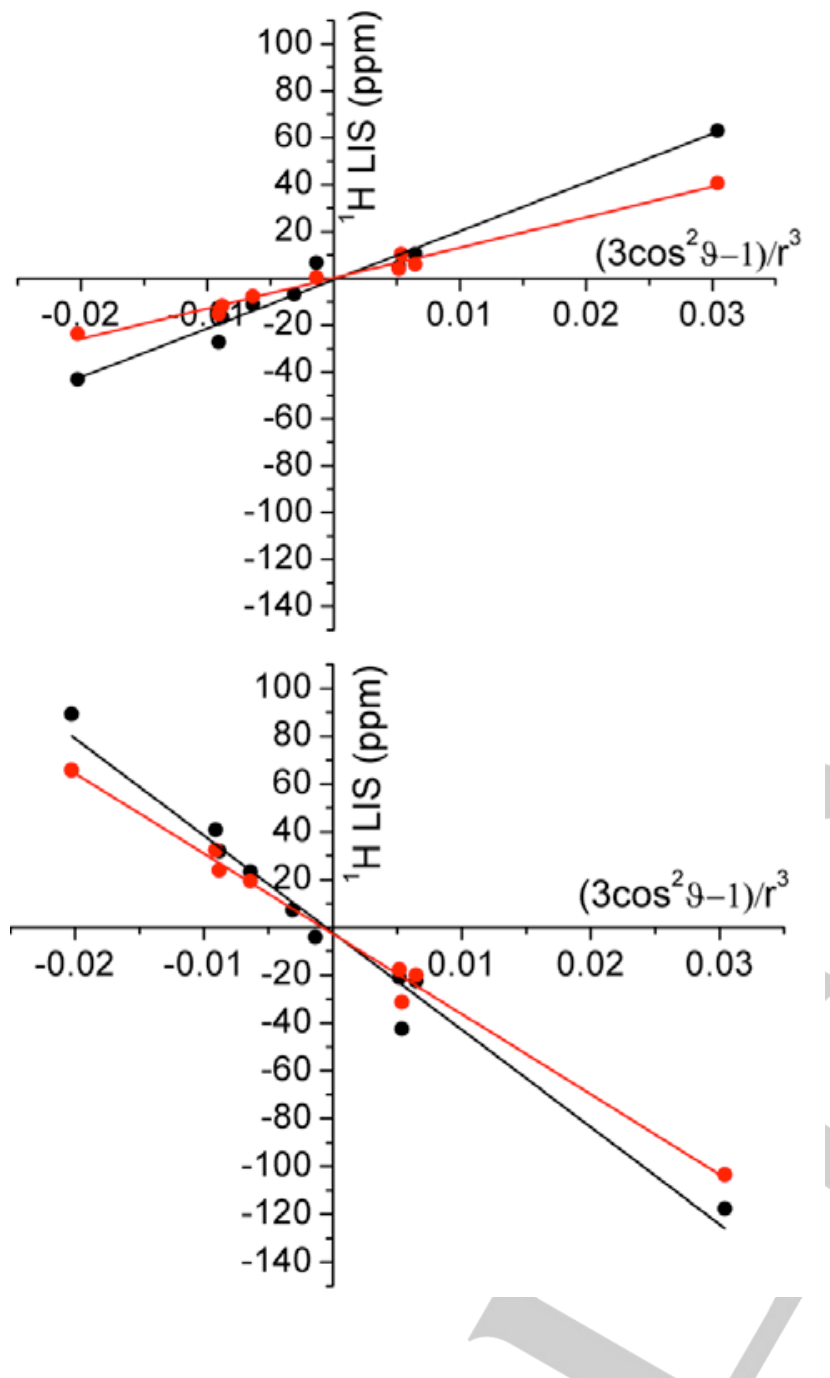

Figure 4. Bleaney plots and linear fits of $\mathrm{YbL}^{\mathrm{py}}{ }^{1} \mathrm{H}$ shifts for the major isomer (black) and minor isomer (red); top: in the absence of fluoride, bottom: in the presence of fluoride.

the absence of fluoride, linear fits of the Bleaney plots give gradients of +2080 (major isomer) and +1300 (minor isomer). On addition of fluoride, the fitted $D_{1}$ values change to -4070 (major isomer) and -3360 (minor isomer). The change from positive to negative $D_{1}$, corresponding to a change in sign of $\mathrm{B}_{0}^{2}$, indicates the same general behaviour as the previously studied ytterbium tetraamide complexes, i.e. a change in nature of the magnetic anisotropy from prolate to oblate on replacement of water with fluoride. ${ }^{[8,9,10]}$ However, in the present case, the magnitudes of $D_{1}$, which represent the asphericity of the magnetic anisotropies, display a much larger change upon fluoride binding. The native $\mathrm{YbL}^{\mathrm{py}}$ complex in the absence of fluoride has a more spherical electron density than $\operatorname{YbDTMA}\left(\mathrm{OH}_{2}\right)\left(D_{1}=+3220\right)$, consistent with a weaker equatorial ligand field, but the fluoride adduct has a considerably more oblate anisotropy compared with $\operatorname{YbDTMA}(F)\left(D_{1}=-890\right)$.

The proton spectra of the major isomers of the fluoride adducts of Ce-EuL ${ }^{\text {py }}$ were assigned directly using COSY, and EXSY/NOESY spectra (Table S4). Reilley plots for major isomers, according to Equation [2], of ${ }^{1} \mathrm{H} L I S /\left\langle S_{Z}\right\rangle$ vs. $C_{J} /\left\langle S_{Z}\right\rangle$, in the presence and absence of fluoride, are shown in Figure 5 and extracted $\mathrm{G}$ and $\mathrm{F}$ values are given in Table 2 .

$$
\frac{L S S}{\left\langle S_{7}\right\rangle}=\frac{C_{y}}{\left\langle S_{7}\right\rangle} G+F
$$

Several things are notable about the data presented in Table 2. Firstly, the slopes of the plots, which provide information about the crystal field parameter, $\mathrm{B}_{0}{ }^{2}$, do not change sign on addition of fluoride, unlike $\mathrm{YbL}^{\mathrm{py}}$ (according to Bleaney plots, above) and those of the tetraamide complexes studied previously. ${ }^{[9]}$ Secondly, the signs of the slopes in the absence of fluoride indicate that $\mathrm{B}_{0}{ }^{2}$ is positive i.e. the sense of the magnetic anisotropy is opposite to the more commonly studied $\mathrm{C}_{4}$ symmetric lanthanide complexes, such as DOTA and the tetraamides. The change in magnitude of $G$ upon fluoride addition (increased approximately five-fold) indicates that the electron density becomes much more anisotropic. Finally, ${ }^{1} \mathrm{H}$ LIS shifts for both isomers of $\mathrm{YbL}^{\mathrm{py}}$ are completely anomalous on the Reilley plot in the absence of fluoride, but the fluoride adduct appears to align with the data for the early lanthanides (Figure S1).

Table 2. Values of $G$ and $F$ for ligand protons derived from Reilley plots in the presence and absence of added fluoride, with the $\mathrm{R}^{2}$ value for each plot.

\begin{tabular}{lllllll}
\hline & \multicolumn{5}{c}{$\mathrm{G}$ (slope) } & \multicolumn{2}{l}{$\mathrm{F}$ (intercept) } & $\mathrm{R}^{2}$ \\
\cline { 2 - 7 } Proton $^{[\mathrm{a}]}$ & $\mathrm{No} \mathrm{F}^{-}$ & $+\mathrm{F}^{-}$ & $\mathrm{No} \mathrm{F}^{-}$ & $+\mathrm{F}^{-}$ & $\mathrm{No} \mathrm{F}^{-}$ & $+\mathrm{F}^{-}$ \\
\hline Arm2 & 1.18 & 4.99 & -0.67 & -0.60 & 0.96 & 0.96 \\
Ax2 & 0.46 & 2.20 & -0.65 & -0.32 & 0.97 & 0.97 \\
Arm1 & 0.47 & 1.79 & -0.95 & -0.74 & 0.94 & 0.96 \\
Eq2 & -0.21 & -1.09 & -1.82 & -1.76 & 0.91 & 0.95 \\
Py1 & -0.40 & -2.44 & -0.07 & 0.07 & 0.90 & 0.87 \\
Eq1 & -0.22 & -1.33 & -1.67 & -1.64 & 0.99 & 1.00 \\
Ax1 & -1.21 & -6.65 & 1.41 & 0.70 & 0.94 & 0.95 \\
\hline
\end{tabular}

[a] $\mathrm{ax}=$ axial, eq = equatorial, py = pyridyl, arm $=\mathrm{CH}_{2}$-py.

These observations can be explained by considering that $L^{p y}$ is a relatively symmetric electron donor acting in the equatorial plane, and therefore coordination of a water molecule in the ninth coordination site is a sufficient to create a dominant axial field. The axial ligand field becomes even more dominant when water is replaced by fluoride. Furthermore, it can be 
inferred that hydration of the ytterbium complex is lower than the complexes of the first half of the series owing to its smaller radius. Alternatively, it is possible that the change in crystal field across the series is due to a change in the $\mathrm{Ln}-\mathrm{OH}_{2}$ bond length, which we previously showed to have a large effect on the magnetic anisotropy. ${ }^{[8]}$ In order to check that the difference between the ytterbium complex the early lanthanides is not due to a structural change in the ligand itself, we evaluated Reuben plots. ${ }^{[19]}$ Plots
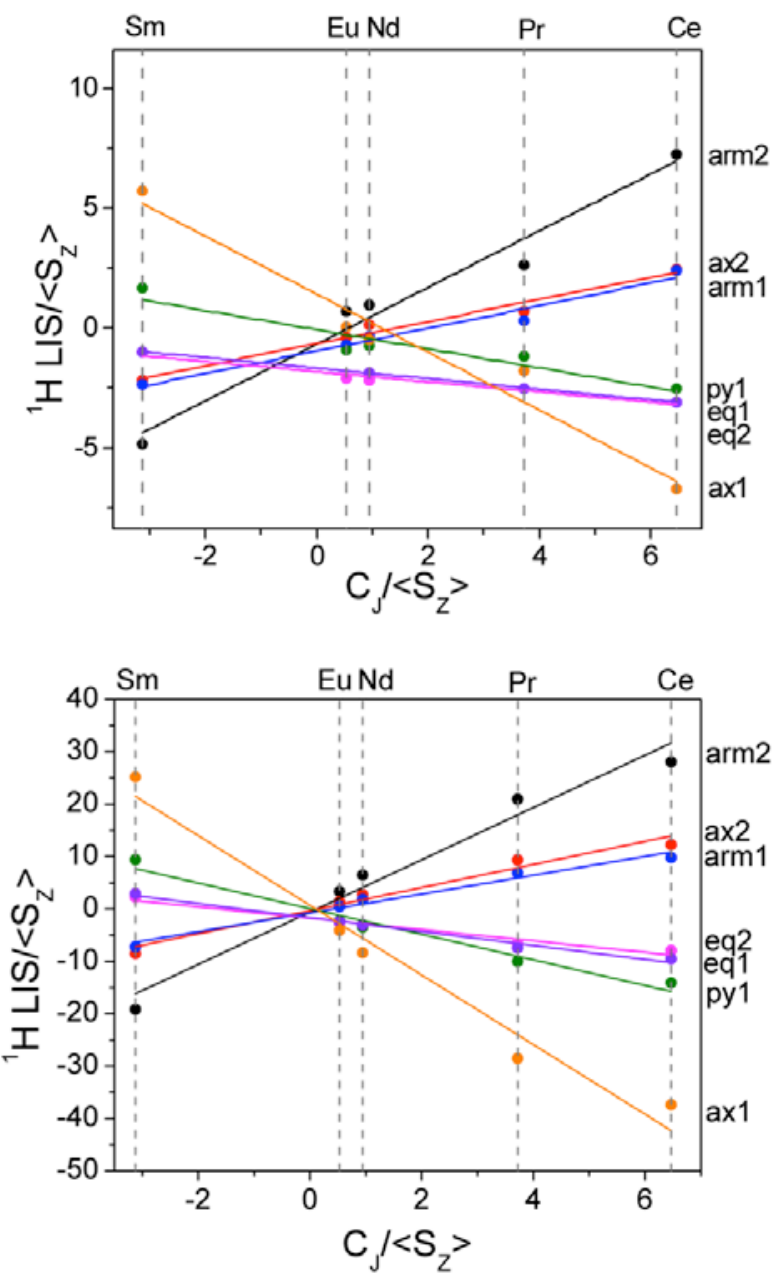

Figure 5. Reilley plots for the major isomers of the early lanthanides in the absence of fluoride (top) and the presence of fluoride (bottom).

including both the early metals and ytterbium are reasonably linear in both the presence and absence of fluoride, indicating that the structure of the macrocyclic ligand does not change across the series (Figures S2 and S3). It is unclear without further analysis at what point this change in behaviour occurs across the series. In contrast, the alignment of $\mathrm{YbL}^{\mathrm{py}}$ shifts with the early lanthanides on the Reilley plots after fluoride addition would imply that the structure of the fluoride adduct is the same across the series. To the best of our knowledge this is the first time a cyclen-based complex has been shown to have the opposite magnetic anisotropy to the hydrated lanthanide ion in the absence of fluoride donors. $C_{3}$ symmetric complexes based on pyridyl-substituted triazacyclononane have magnetic anisotropy of the same sense as the early complexes of $L^{\text {py }}$ since the weak pyridyl donors lie in the equatorial plane leaving the dominant ligand field in the axial direction. ${ }^{[20]}$

The change in $\mathrm{F}$ value on addition of fluoride is generally small in comparison to the changes observed previously for complexes of DTMA. Larger changes are observed for the axial protons and pyridyl proton 1 . Nuclei on the pyridyl rings would be expected to be more sensitive to changes in electron density via the through-bond interaction than nuclei on aliphatic portions of the ligand. The less pronounced changes in the contact shift contribution in this system compared with LnDTMA are likely to be due to the electron distribution changing in magnitude but not sense.

As with the tetraamide systems previously studied, the presence of the fluoride adduct can be evidenced also in the ${ }^{19} \mathrm{~F}$ NMR spectrum. When fluoride is added to EuL ${ }^{\text {py }}$, two peaks are observed, in addition to the free fluoride and triflate peaks, at 311 and -449 ppm (Figure S4). These correspond to the bound fluoride of the two different isomers; the peak at $-449 \mathrm{ppm}$ is roughly $3 \%$ of the intensity of that at $311 \mathrm{ppm}$, in line with the ratio observed in the ${ }^{1} \mathrm{H}$ NMR spectrum. Saturation transfer experiments confirm that these bound fluoride peaks are in exchange with free fluoride. For the yttrium complex, bound fluoride peaks are observed as doublets at -0.4 and $-20.7 \mathrm{ppm}$ in a ratio of ca. 8:1, again correlating with the isomer ratio in the ${ }^{1} \mathrm{H}$ NMR spectrum, and coupling constants of 54 and $57 \mathrm{~Hz}$ respectively. Doublet fine structure was observed previously with the YDTMA(F) adduct and HMQC was used to demonstrate that this is due to ${ }^{89} \mathrm{Y}^{-19} \mathrm{~F}$ coupling. ${ }^{[9]}$ This fine structure confirms that the stoichiometry of the binding event in this case is 1:1 (in line with the model used to fit the binding measurements described above). Further evidence of a 1:1 stoichiometry is obtained from $a^{1} \mathrm{H}$ DOSY spectrum of EuL ${ }^{\text {py }}$ with half an equivalent of $\mathrm{NaF}$ added (Figure S5). Peaks corresponding to the hydrated complex and the fluoride adduct are found to have very similar diffusion coefficients suggesting that they are of comparable size. This contrasts with the aforementioned $C_{2}$ symmetric system studied by Charbonnière et al., where intermolecular forces are postulated to induce dimer formation in solution. ${ }^{[13]}$

\section{Luminescence}

The effect of binding fluoride on the crystal field can also be studied using luminescence. The changes in the emission spectra of EuL ${ }^{\text {py }}$ and $\mathrm{YbL}^{\mathrm{py}}$ in aqueous solution upon addition of an excess of fluoride are shown in Figure 6. Dramatic changes were observed in the shape and intensity of the spectra consistent with a significant change in the crystal field upon fluoride binding. The form of the spectra was found to be concentration dependent- while the cause of this is uncertain, aggregation might be expected to play a role.

The nature of the crystal field splitting can be directly gleaned from the splitting of the ${ }^{5} D_{0} \odot{ }^{7} F_{1}$ band of the europium complex. In the absence of fluoride the Stark splitting of this band cannot be resolved, which is consistent with the small crystal field splitting indicated by ${ }^{1} \mathrm{H}$ NMR. On addition of fluoride, 
the splitting of this band is considerably expanded. The magnitude of the splitting is $339 \mathrm{~cm}^{-1}$ which equates to $\mathrm{B}_{0}^{2}=$ $1130 \mathrm{~cm}^{-1}$ using a conversion factor of 3.33. ${ }^{[21]}$ Furthermore, the sign of $B_{0}^{2}$ is apparent from the relative energies of the $A$ and $E$ sublevels- since the A level is higher in energy than the $E$ level, $\mathrm{B}_{0}{ }^{2}$ is positive, consistent with the results of the Reilley plots (above). $\mathrm{A} \mathrm{B}_{0}^{2}$ value of $+1130 \mathrm{~cm}^{-1}$ is unusually high, with such large magnitudes usually being negative. ${ }^{[22]}$ This is a result of the combination of the strong axial fluoride ligand and the relatively weak equatorial donors of the macrocyclic ligand, providing a highly oblate $4 \mathrm{f}$ electron density.
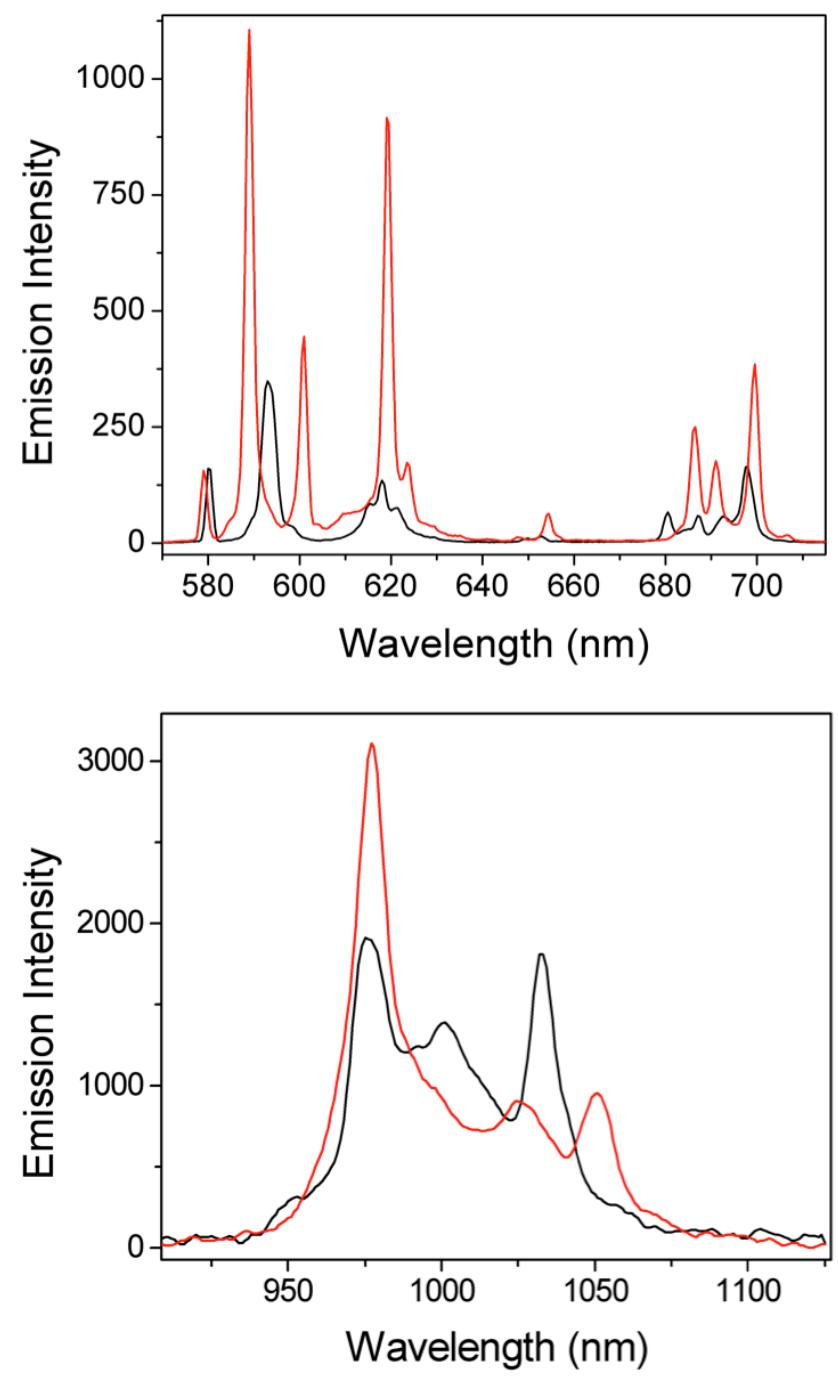

Figure 6. Emission spectra of $\mathrm{EuL}^{\mathrm{py}}$ (top) and $\mathrm{YbL}^{\mathrm{py}}$ (bottom) in $\mathrm{D}_{2} \mathrm{O}$ before (black) and after (red) addition of an excess of sodium fluoride.

\section{Conclusions}

The results described here show, once again, the importance of the local crystal field in defining the behaviour of lanthanide complexes in solution. The observation that a well-defined N8 donor set can be used to change the sense of the magnetic anisotropy at a lanthanide centre has significant implications for control of spectroscopic properties in such systems. This bears out the work of those in the field of molecular magnetism who have suggested that the local crystal field can be used to control behaviour at low temperature. It also strengthens the growing body of evidence that the structure of complexes must invariably be treated as a whole.

The differences in crystal field between hydrated and fluoride-bound complexes are also likely to have profound consequences for the application of lanthanide complexes in devices. It is now abundantly clear that, even at room temperature, Boltzmann populations of the $m_{j}$ states of a lanthanide centre can be controlled and changed through coordination chemistry, and particularly through variation of the donor set. Such variations, themselves the consequence of changes to the relative energies of these states, offer the potential for a new approach to controlling the behaviour of lanthanide containing devices, and we are now working to demonstrate these possibilities.

\section{Experimental Section}

Commercially available reagents and solvents were used without further purification. The complexes were synthesised by the published procedure, ${ }^{[11]}$ which was modified in the case of the ytterbium and cerium complexes (see SI). Single crystal X-ray diffraction data were collected using an Oxford Diffraction Supernova dual-source diffractometer equipped with a $135 \mathrm{~mm}$ Atlas CCD detector. NMR spectra were recorded on a Bruker Avance III HD $400\left({ }^{1} \mathrm{H}=400 \mathrm{MHz},{ }^{19} \mathrm{~F}=376 \mathrm{MHz}\right)$ or a Bruker Avance III HD $500\left({ }^{1} \mathrm{H}=500 \mathrm{MHz},{ }^{19} \mathrm{~F}=470 \mathrm{MHz}\right)$ spectrometer. NMR spectra of paramagnetic complexes with wide spectral width were obtained using pulses sufficiently short to ensure reasonably uniform excitation over the observed bandwidth, and with acquisition and recycle times matched to the relaxation characteristics of the lanthanide complexes (repetition time typically $100 \mathrm{~ms}$ ). EXSY spectra were recorded at $500 \mathrm{MHz}$ using a gradient selected NOESY sequence with a mixing time of $0.1 \mathrm{~s}$. Luminescence measurements were obtained using a HORIBA FluoroLog3 fluorimeter. Spectra of EuL ${ }^{\text {py }}$ were recorded in fluorescence mode exciting at $395 \mathrm{~nm}$ with an exit slit of 1 $\mathrm{nm}$ slit. Spectra of $\mathrm{YbL}^{\text {py }}$ were recorded with the same instrument adapted with a Hamamatsu R5509-42 NIR PMT InGaAs detector cooled to $-80^{\circ} \mathrm{C}$. An excitation wavelength of $275 \mathrm{~nm}$ and an exit slit of $5 \mathrm{~nm}$ were used; multiple accumulations were necessary. Further experimental details are given in the supporting information.

\section{Acknowledgements}

The Authors acknowledge the Universities of Oxford and Durham for support. The research leading to these results has received funding from the European Research Council under the European Union's seventh Framework Programme (FP7/2007_2013)/ERC-Advanced Grant Agreement Number 267426. 
Keywords: lanthanide • fluoride-binding • magnetic anisotropy • crystal field • spectroscopy

[1] (a) D. N. Woodruff, R. E. P. Winpenny, R. A. Layfield, Chem. Rev. 2013 113, 5110-5148. (b) P. Caravan, Chem. Soc. Rev. 2006, 35, 512-523. (c) S. Faulkner and O. A. Blackburn, Chapter 8 in The Chemistry of Molecular Imaging (eds. N. Long and W.T. Wong),Wiley (Chichester), 2015. (d) I. Hemmilä, V. Laitala in Lanthanide Luminescence, Springer Series on Fluorescence, Vol. 7, Springer, Heidelberg, 2011.

[2] (a) B. Bleaney, J Magn Reson 1972, 8, 91-100. (b) B. Bleaney, C. M. Dobson, B. A. Levine, R. B. Martin, R. J. P. Williams, A. V. Xavier, J. Chem. Soc., Chem. Commun. 1972, 791b-793.

[3] (a) J. Reuben, G. A. Elgavish, in Handbook on the Physics and Chemistry of Rare Earths, ed. K. A. Gschneidner, L. Eyring, Elsevier, 1979, vol. 4, pp. 483-514. (b) J. H. Forsberg, in Handbook on the Physics and Chemistry of Rare Earths, ed. K. A. Gschneidner, L. Eyring Elsevier, 1996, vol. 23, pp. 1-68. (c) J. A. Peters, J. Huskens, D. J. Raber, Prog. Nucl. Magn. Reson. Spectrosc. 1996, 28, 283-350. (d) R. R. Sharp, in Nuclear Magnetic Resonance, RSC, 2001, 30, 477-526. (e) C. Piguet, C. F. G. C. Geraldes, in Handbook on the Physics and Chemistry of Rare Earths, ed. K. A. Gschneidner, J.-C. G Bünzli, V. K. Pecharsky, Elsevier, 2003, vol. 33, pp. 353-463.

[4] O. A. Blackburn, R. M. Edkins, S. Faulkner, A. M. Kenwright, D. Parker, N. J. Rogers, S. Shuvaev, Dalton Trans. 2016, DOI: 10.1039/C6DT00227G

[5] (a) B. R. McGarvey, J. Magn. Reson. 1979, 33, 445-455. (b) E. W. Stout Jr, H. S. Gutowsky, J. Magn. Reson. 1976, 24, 389-398. (c) V. Mironov, Y. Galyametdinov, A. Ceulemans, C. Görller-Walrand, K. Binnemans, Chem. Phys. Lett. 2001, 345, 132-140. (d) V. S. Mironov, Y. G. Galyametdinov, A. Ceulemans, C. Görller-Walrand, K. Binnemans, J. Chem. Phys. 2002, 116, 4673-4685.

[6] (a) G. T. P. Charnock, I. Kuprov, Phys. Chem. Chem. Phys. 2014, 16, 20184-20189. (b) N. F. Chilton, D. Collison, E. J. L. Mclnnes, R. E. P. Winpenny, A. Soncini, Nature Communications 2013, 4, 2551. (c) F Gendron, K. Sharkas, J. Autschbach, J. Phys. Chem. Lett. 2015, 6, 2183-2188.

[7] See for example: J. D. Rinehart, J. R. Long, Chem. Sci. 2011, 2, 2078
[8] O. A. Blackburn, N. F. Chilton, K. Keller, C. E. Tait, W. K. Myers, E. J. L. McInnes, A. M. Kenwright, P. D. Beer, C. R. Timmel, S. Faulkner Angew. Chem. Int. Ed. 2015, 54, 10783-10786.

[9] O. A. Blackburn, A. M. Kenwright, P. D. Beer, S. Faulkner, Dalton Trans. 2015, 44, 19509-19517.

[10] O. A. Blackburn, J. D. Routledge, L. B. Jennings, N. H. Rees, A. M. Kenwright, P. D. Beer, S. Faulkner, Dalton Trans. 2016, 45, 30703077.

[11] L. S. Natrajan, N. M. Khoabane, B. L. Dadds, C. A. Muryn, R. G. Pritchard, S. L. Heath, A. M. Kenwright, I. Kuprov, S. Faulkner, Inorg Chem 2010, 49, 7700-7709.

[12] P. Kuzmic, Anal. Biochem. 1996, 237, 260-273.

[13] (a) L. M. P. Lima, A. Lecointre, J.-F. Morfin, A. de Blas, D. Visvikis, L. J. Charbonnière, C. Platas-Iglesias, R. Tripier, Inorg Chem 2011, 50 , 12508-12521. (b) R. Tripier, C. Platas-Iglesias, A. Boos, J.-F. Morfin, L. Charbonnière, Eur. J. Inorg. Chem. 2010, 2735-2745. (c) C.M.G. dos Santos, T. Gunnlaugsson, Dalton Trans., 2009, 4712-4721.

[14] T. Liu, A. Nonat, M. Beyler, M. Regueiro-Figueroa, K. Nchimi Nono, O. Jeannin, F. Camerel, F. Debaene, S. Cianférani-Sanglier, R. Tripier, et al., Angew. Chem. Int. Ed. 2014, 53, 7259-7263.

[15] S. J. Butler, Chem. Commun. 2015, 51, 10879-10882.

[16] (a) A. J. Amoroso, A. M. C. Thompson, J. C. Jeffery, P. L. Jones, J. A. McCleverty, M. D. Ward, J. Chem. Soc., Chem. Commun. 1994, 2751 2752. (b) P. L. Jones, A. J. Amoroso, J. C. Jeffery, J. A. McCleverty, E. Psillakis, L. H. Rees, M. D. Ward, Inorg. Chem. 1997, 36, 10-18.

[17] (a). N. Reilley, B. Good, J. Desreux, Anal. Chem. 1975, 47, 2110-2116. (b) S. Rigault, C. Piguet, J.-C. G. Bünzli, J. Chem. Soc., Dalton Trans. 2000, 2045-2053. (c) S. Rigault, C. Piguet, G. Bernardinelli, G Hopfgartner, J. Chem. Soc., Dalton Trans. 2000, 4587-4600.

[18] S. Aime, M. Botta, G. Ermondi, Inorg Chem 1992, 31, 4291-4299.

[19] (a) J. Reuben, Journal of Magnetic Resonance 1982, 50, 233-236. (b) C. Platas, F. Avecilla, A. de Blas, C. F. G. C. Geraldes, T. RodríguezBlas, H. Adams, J. Mahía, Inorg Chem 1999, 38, 3190-3199.

[20] A. M. Funk, P. H. Fries, P. Harvey, A. M. Kenwright, D. Parker, J. Phys. Chem. A 2013, 117, 905-917.

[21] C. Görller-Walrand, E. Huygen, K. Binnemans, L. Fluyt, Journal of Physics: Condens. Matter 1994, 6, 7797-7812.

[22] a) A. M. Funk, K.-L. N. A. Finney, P. Harvey, A. M. Kenwright, E. R. Neil, N. J. Rogers, P. Kanthi Senanayake, D. Parker, Chem. Sci. 2015, 6, 1655-1662. (b) C. Görller-Walrand and K. Binnemans, in Handbook on the Physics and Chemistry of Rare Earths, ed. K. A. Gschneidner and L. Eyring, Elsevier, 1996, vol. 23, pp. 121-283. 
Entry for the Table of Contents (Please choose one layout)

Layout 1:

\section{FULL PAPER}

Coordination of fluoride to lanthanide complexes of tetrapicolyl-appended cyclen derivatives enhances the magnetic anisotropy.
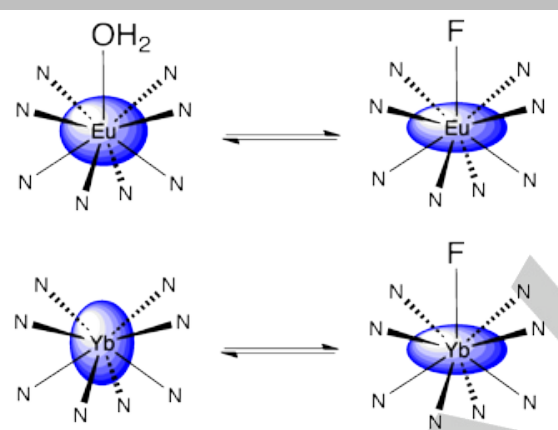

Octavia A. Blackburn, Alan M. Kenwright, Andrew R. Jupp, Jose M. Goicoechea, Paul D. Beer, and Stephen Faulkner

Page No. - Page No.

Fluoride Binding and Crystal Field Analysis of Lanthanide Complexes of Tetrapicolyl-Appended Cyclen 